\title{
Correlation of the annual temperature reconstructed with $\mu \_X R F-S R$ method and pollen data from varved sediments of Lake Kucherla, the Altai Mountains, for the last 500 years
}

\author{
Rudaya N.A. ${ }^{1,2}$, Darin A.V. ${ }^{2}$ \\ ${ }^{1}$ PaleoData Lab, Institute of Archaeology and Ethnography SB RAS, Av. Acad. Lavrentieva, 17, Novosibirsk, 630090, Russia \\ ${ }^{2}$ Institute of Geology and Mineralogy SB RAS, Av. Acad. Koptyuga, 3, 630090, Novosibirsk, Russia
}

\begin{abstract}
This paper presents an attempt to correlate the temperature curve built by the transfer function method based on data from elemental analysis $\mu_{-}$XRF-SR and the results of pollen analysis of the core of the Kucherla Lake bottom sediments in the 1500 - 2016 CE.

A comparison of geochemical reconstruction with pollen data was carried out by calculation of pair correlation coefficients. For this, temperatures were averaged to intervals corresponding to the interval of the pollen sample metric size $(10 \mathrm{~mm})$. Depending on the age-depth model the time interval of the pollen sample varied from 4 to 12 years. After that, a pairwise comparison of one-year data of temperature reconstruction and palynological analysis was performed. The paired correlations of mean annual temperatures obtained based on geochemical studies of the Kucherla Lake core by the $\mu$ XRF-SR method and pollen data showed a significant negative correlation between the content of terrestrial herbs, grasses, and wormwood and mean annual temperatures. This can be explained by the expansion of the steppe area during cold periods, probably accompanied by a decrease in precipitation.
\end{abstract}

Keywords: $\mu$ XRF-SR, pollen, transfer function, Altai, late Holocene

\section{Introduction}

Lake bottom sediments are paleoarchives, which allow obtaining climatic reconstructions of high temporal resolution. The special interest of researchers causes the bottom sediments with annual layers (varvs), providing the requisite level of detail and accuracy of reconstructions (Zolitschka et al., 2015).

In glacial lakes, varves are formed by seasonal supplies of glacial mud and consist of large siltstone particles (spring-summer layer) and fine clay deposited in winter. The use of modern analytical methods makes it possible to study such bottom sediments with annual and even seasonal resolution, which provides new approaches in paleoclimatic studies (Brauer, 2004; Alexandrin et al., 2018). A mandatory requirement for such research is the use of instrumental analytical techniques with submillimeter spatial resolution, such as hyperspectroscopy (Butz et al., 2015), XRF core scanning (Croudace et al., 2019), and $\mu$-RFA with synchrotron excitation ( $\mu$ XRFF-SR) (Darin et al., 2013).

The high temporal resolution allows direct comparison of the set of received proxies with the data of regional meteorological observations in the last century with the finding of climatic indicators and construction of transfer functions for reconstructed parameters.

The palynological method is the basic method that provides information about past vegetation in the region. This paper presents an attempt to correlate the temperature curve built by the transfer function method based on data from elemental analysis $\mu$ XRFSR and the results of pollen analysis of the core of the Kucherla Lake bottom sediments in the 1500 - 2016 CE.

\section{Study site and methods}

The Kucherla Lake (49051-53`N; 86024-25`E) is situated in the upper part of the Kucherla River valley in the axial part of the Katun Range. The lake is located at an altitude of $1790 \mathrm{~m}$ asl. The length of the lake is $5 \mathrm{~km}$, width $1 \mathrm{~km}$, the maximum depth reaches $45 \mathrm{~m}$. The total area of the lake is 321 ha. The lake has glacier supply from the Kucherla glacier. The lake is running; the river Kucherla flows into and out of it. Three small streams flow from the western and eastern slopes of the basin (Fig. 1). At a distance of $20 \mathrm{~km}$ from the lake is the Kara-Turek meteorological station with continuous observations since $1940 \mathrm{CE}$. 
The core of Lake Kucherla was obtained from ice using a gravity corer in March 2018. The length of the core, selected in the deepest part of the lake from a depth of $45 \mathrm{~m}$, is $1120 \mathrm{~mm}$. In the process of core obtaining, special attention was paid to the preservation of the water-sediment boundary, which allowed further counting of annual layers from the year of sampling.

Temperature reconstruction for the last 1400 years was obtained using data from $\mu$ XRFSR core scanning and calibration by instrumental data from the Kara-Turek meteorological station in the 1940-2016 CE. The detailed procedure of temperature reconstruction based on lithologic and geochemical data is considered in Darin et al. (submitted).

For more detailed estimations of the accuracy of the obtained reconstruction, comparison with regional glaciological (Eichler et al., 2009) and dendroclimatic (Syromyatina et al., 2010) data of the annual temporal resolution was performed (Fig. 2).

A total of 20 samples were taken for pollen analysis at $6 \mathrm{~cm}$ intervals. The samples were prepared according to standard methods (Faegri, Iversen, 1989). Each sample contained at least 300 grains of pollen and spores, as well as nonpollen palynomorphs (NPP). The pollen diagram is constructed in the Tilia software (Fig. 3).

A comparison of geochemical reconstruction with pollen data was carried out by calculation of pair correlation coefficients. For this, temperatures were averaged to intervals corresponding to the interval of the pollen sample metric size $(10 \mathrm{~mm})$. Depending on the age-depth model (Darin et al., submitted) the time interval of the pollen sample varied from 4 to 12 years. After that, a pairwise comparison of one-year data of temperature reconstruction and palynological analysis was performed. For comparison, the interval between 1500 - 2016 CE was chosen as having reliable age and temperature characteristics (Fig. 2).

\section{Results and Interpretation}

As a result of this study, three palynological parameters with paired correlation coefficients above the critical value $(n=14, p=0.05, k=0.53)$ are selected. The given parameters include the percentage of terrestrial herbs $(\mathrm{r} 2=-73)$; Poaceae (r2=-0.59) and Artemisia (r2=-61).

The high pollen content of herbs, and especially steppe Artemisia, in core samples probably reflects the upward transport from the underlying steppe belt. The negative correlation between temperature and herbaceous pollen can be interpreted as a tendency to expand steppes during cold periods, probably accompanied by a decrease in precipitation. The reconstruction of precipitation and its comparison with palynological and temperature data is in progress.

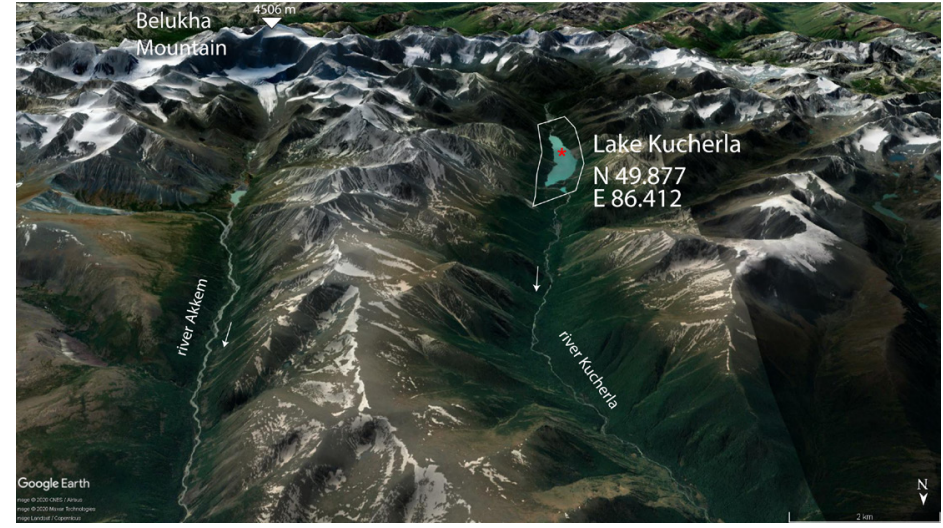

Fig.1. An object of study - Lake Kucherla, Katunski Ridge, the Altai Mountains. An asterisk marks the place of coring in 2018.

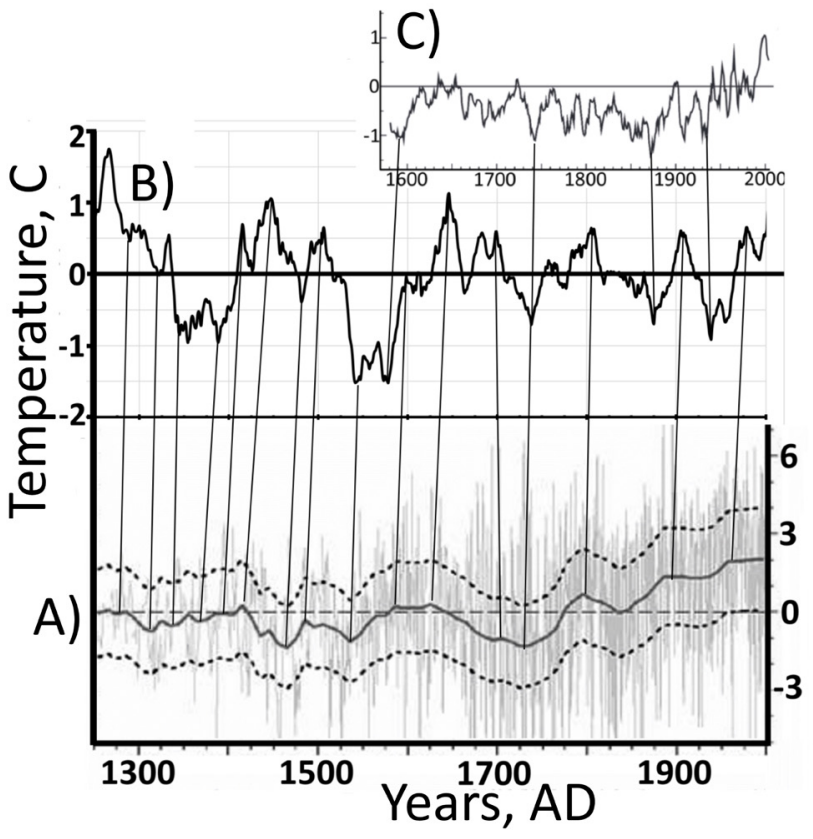

Fig.2. Comparison of regional temperature reconstructions of high temporal resolution.

A) Temperature reconstruction based on the $\mathrm{d} 180$ measurement of Belukha glacier core. The data represent anomalies, from the average for 1250-2001. Separate values (grey), the average for 10 years, and error interval (black, dotted) are shown (Eichler et al., 2009).

B) Reconstruction based on lithological and geochemical measurements of sediments of Lake Kucherla recalculated as anomalies from the average for 1250-2001 (this study).

C) Deviations in the average summer air temperature in the Altai region according to the dendrochronological data, calibrated according to the instrumental data of the Ust-Koksa meteorological station. 7-year moving average and deviations from the 1940-1994 period are presented (Syromiatina et al., 2010). 


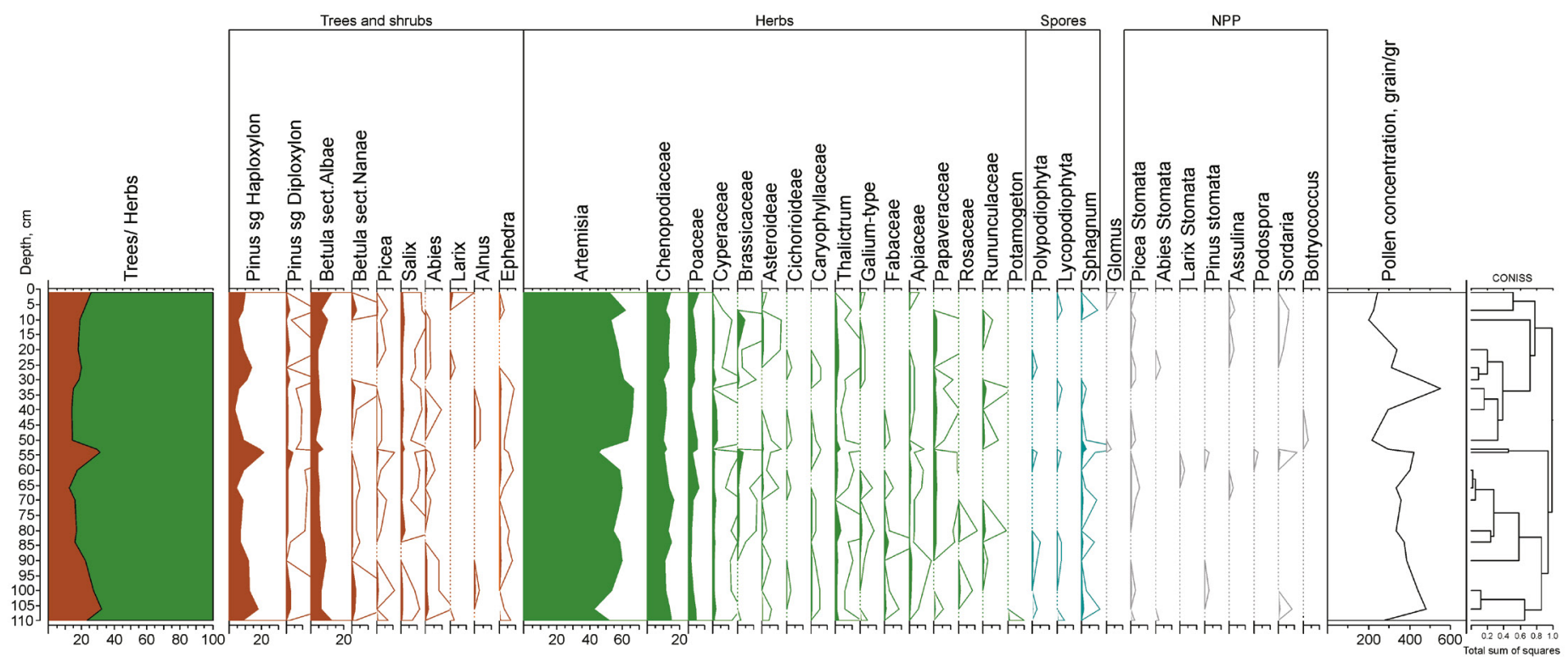

Fig.3. Pollen diagram of Lake Kucherla bottom sediments

\section{Conclusion}

The paired correlations of mean annual temperatures obtained based on geochemical studies of the Kucherla Lake core by the $\mu_{-}$XRF-SR method and pollen data showed a significant negative correlation between the content of terrestrial herbs, grasses, and wormwood and mean annual temperatures. This can be explained by the expansion of the steppe area during cold periods, probably accompanied by a decrease in precipitation.

\section{Acknowledgments}

The work was supported by RSF project No. 20-17-00110 and partial support of RFBR project No. 19-05-50046 (analytical microstratigraphy). We thank Ivan Grekov for cartographical assistance.

\section{References}

Alexandrin M., Dolgova E., Grachev A. et al. 2018. Annual sedimentary record from lake Donguz-orun (central Caucasus) constrained by high resolution SR-XRF analysis and its potential for climate reconstructions. Frontiers in Earth Science 6: 158-162. DOI: 10.3389/feart.2018.00158

Brauer A. 2004. Annually laminated lake sediments and their paleoclimatic relevance. In: Fischer H. et al. (eds) The Climate in Historical Times. GKSS School of Environmental Research. Springer, Berlin, Heidelberg, pp. 109-127. DOI: 10.1007/978-3-662-10313-5_7
Butz C., Grosjean M., Fischer D. et al. 2015. Hyperspectral imaging spectroscopy: A promising method for the biogeochemical analysis of lake sediments. Journal of Applied Remote Sensing 9(1): 096031. DOI: 10.1117/1.JRS.9.096031

Croudace I., Löwemark L., Tjallingii R., Zolitschka B. 2019. Current perspectives on the capabilities of high resolution $X R F$ core scanners. Quaternary International 514: 5-15. DOI: 10.1016/j.quaint.2019.04.002

Darin A.V., Chu G., San C. et al. 2020. Quantitative reconstruction of the Altai region annual air temperatures over the past 1400 years according to analytical microstratigraphy of Lake Kucherlinskoe varved clays. Izvestiya RAN (Akad. Nauk SSSR). Seriya Geograficheskaya. (in Russian)

Darin A.V., Kalugin I.A., Rakshun Ya.V. 2013. Scanning $\mathrm{x}$-ray microanalysis of bottom sediments using synchrotron radiation from the BINP VEPP-3 storage ring. Bulletin of the Russian academy of sciences: physics 77(2): 182-184. DOI: 10.7868/S0367676513020105

Eichler A., Olivier S., Henderson K. et al. 2009. Temperature response in the Altai region lags solar forcing. Geophysical research letters 36(1): L01808. DOI: 10.1029/2008GL035930

Fægri K., Iversen J. 1989. Textbook of Pollen Analysis, fourth ed. In: John Wiley \& Sons, Chichester.

Syromiatina M.V., Moskalenko I.G., Tchistiakov K.V. 2010. Climate change trends in Altai against the background of global climate changes (according to instrumental and dendrochronological data). Saint Petersburg University Bulletin. Series 7. Geology. Geography 3: 82-91. DOI: 10.18551/rjoas.2015-07.01

Zolitschka B., Francus P., Ojala A.E., Schimmelmann A. 2015. Varves in lake sediments - A review. Quaternary Science Reviews 117: 1-41. DOI: 10.1016/j.quascirev.2015.03.019 